\title{
Assessment of the Procedural Gases Influence at Turning Technology
}

Miloslav Ledvina, Štěpánka Dvořáčková

Department of Machining and Assembly, Faculty of Mechanical Engineering, Technical University of Liberec, 46117 Liberec. Czech Republic., E-mail: miloslav.ledvina@tul.cz, stepanka.dvorackova@tul.cz

This paper deals with the assessment of the procedural gases progressive cooling methods and cooling by procedural liquids at turning technology on the final workpiece surface quality. Turning by using liquefied $\mathrm{CO}_{2}$, liquefied nitrogen and subcooled air supplied through the vortex tube was compared with the turning without process medium (taken as reference conditions) and with two procedural liquids EOPS 1030 and HOCUT 795 B. At evaluation effect of procedural gases there were monitored acting forces, cutting tool cooling rate and the machined layer of the material, cutting tool durability and cut surface quality which was characterized by surface roughness and dimensional accuracy. During the experimental part there were used devices as lathe SU50, piezoelectric dynamometer, the evaluation unit and profilometer. This issue was solved within solving the project TACR TA03010492.

Keywords: Turning, Cooling by Gas, Acting Forces, Tool Durability, Temperature, Surface Quality.

\section{Acknowledgement}

This paper was realized though the financial support of the Czech Republic state budget means - Technological Agency of the Czech Republic (project TA03010492).

\section{References}

[1] BARTUŠEK, T., JERSÁK, J. (2009). Metoda MQL a její vliv na technologické parametry procesu broušení. Strojirrenská technologie. Rec. prof. Mádl. 14. roč., březen, č. 1 s. 12-18. ISSN 1211-4162.

[2] ČEP, R. Technologie II - 1. díl. Skriptum. VŠB Ostrava [online]. [cit. 12.12.2015]. Dostupné z < http://homel.vsb.cz/ cep77/PDF/skripta_Technologie_II_1dil.pdf >

[3] FOREJT, M., PÍŠKA, M. (2006). Teorie obrábění, tváření a nástroje. 1.vyd. Brno: Akademické nakladatelství CERM, 225 s. ISBN 80-2374-9.

[4] GREENWOOD, N. N., EARNSHAW, A. (1993). Chemie prvků I. Informatorium, Praha, 793 s. ISBN 80-8542738-9.

[5] HOLEŠOVSKÝ, F., JERSÁK, J. aj., (2005). Terminologie obrábění a montáže - 1. vyd. Ústí nad Labem: Universita J. E. Purkyně, ÚTŘV, 2005, Kapitola: Teorie a technologie obrábění, s. 7-66, ISBN 80-7044-616-1.

[6] KOCMAN, K. (2001). Aktuální přiručka pro technický úsek :Svazek 7. Obrábění. Praha: Dashöfer, ISBN 80902247-2-5.

[7] KOCMAN, K., PROKOP, J. (2005). Technologie obrábění - 2. vyd., Brno: Akademické nakladatelství CERM Brno, s.r.o., 270 s., ISBN 80-214-3068-0.

[8] KROUPA, A. Kryogenní technologie chlazení reaktorů a vymrazování VOC pro chemii a farmacii. Chemagazin [online]. 2009/3 [cit. 13.12.2015]. Dostupné z: < http://www.chemagazin.cz/userdata/chemagazin_2010/file/chxix_3_cl6.pdf >

[9] LEDVINA, M., KARÁSEK J., DVOŘÁČKOVÁ Š. (2014). Hodnocení vlivu procesních plynů při technologii frézování. Konference ICTKI 2014, Strojirenská technologie, ročník XVIII, č. 3, s. 32-37, ISSN 1211-4162

[10]LEDVINA, M., KARÁSEK, J., DVOŘÁČKOVÁ, Š. (2015). Hodnocení vlivu procesních plynů při technologii frézování. Strojírenská technologie Plzeň 2015: sborník abstraktů: VI. ročník mezinárodní konference konaná ve dnech 3. - 4. 2015 v Plzni. Vyd. 1. Plzeň: ZČU v Plzni, s. 137-145. ISBN 978-80-261-0304-2

[11]LONTECH, Vírové trubice [online]. Lontech.cz [cit. 09.12.2015]. Dostupné $\mathrm{z}<\mathrm{http}: / /$ www.lontech.cz/clanky-1.-virove-trubice.html >.

[12]MÁDL, J., HOLEŠOVSKÝ, F. (2010). Strojírenská technologie pro moderní výrobu - 1. vyd. FVTM : UJEP Ústí n. Labem. 56s. ISBN 987-880-7414-218-5.

[13]MM SPECTRUM, Následné doladění pro obráběcí stroje. MM spektrum [online]. 2012/10 [09.12.2015]. Dostupné $\mathrm{z}<\mathrm{http} / / /$ www.mmspektrum.com/novinka/nasledne-doladeni-pro-obrabeci-stroje.html >. 
[14]MM SPECTRUM, V budoucnosti budou těžce obrobitelné materiály obráběny za velmi nízkých teplot. MM spektrum [online]. 2012/6 [cit. 19.11.2015]. Dostupné z < http://www.mmspektrum.com/novinka/v-budoucnosti-budou-tezce-obrobitelne-materialy-obrabeny-za-velmi-nizkych-teplot.html >.

[15]PAGÁČ, M. Walter představil na veletrhu EMO kryogenní chlazení. Průmysl.cz [online]. 2013 [cit. 17.11.2015]. Dostupné z < http://www.prumysl.cz/walter-predstavil-na-emo-kryogenni-chlazeni/ >

[16]PAZDERA, J. Oxid uhličitý v roli ochrance životního prostředí. Osel.cz [online]. 2005 [cit. 07.11.2015]. Dostupné $\mathrm{z}<\mathrm{http}: / /$ www.osel.cz/index.php?obsah=6\&akce=showall\&clanek=1216 >

[17]PETŘíK, V. (2011). Využití různých systémů chlazení pro obrábění materiálů, Diplomová práce, UTB ve Zlíně.

[18]POPOV, A. Obrobitelnost materiálů a řezivost řezných nástroju (podklad pro výuku Teorie obrábění), [cit. 08.07.2015], dostupné na http://www.technomat.cz/data/katedry/kom/KOM_TO_ PR_13_CZE_Popop_Obrobitelnost_materialu_a_rezivost_reznych_nastroju.pdf.

[19]ŘASA, J.; GABRIEL, V. (2000). Strojírenská technologie 3 - 1. díl - Metody, stroje a nástroje pro obrábění. 1. vyd. Praha: Scientia, spol. s.r.o., 256s. ISBN 80-7183-207-3.

[20]STRUŠKA, O. (2011). Kryogenní chlazení při broušení kovových a plastových materiálů, Bakalářská práce, UTB ve Zlíně, [cit. 13.12.2015]. Dostupné z $\mathrm{z}$ https://dspace.k.utb.cz/bitstream/handle/10563/17614/stru\%C5\%A1ka_2011_bp.pdf?sequence=1 >. 